\title{
Fontes Energéticas e Níveis de Suplementação para Vacas em Pastagem de Capim-Marandu (Brachiaria brizantha Hochst ex. A. Rich Stapf) no Inverno ${ }^{1}$
}

\author{
Renata Alves Agulhon², Clóves Cabreira Jobim³ ${ }^{3}$ Antônio Ferriani Branco ${ }^{3}$, Moysés Calixto Júnior ${ }^{4}$
}

RESUMO - Quarenta vacas de corte (330 kg) foram distribuídas em delineamento inteiramente casualizado, em esquema fatorial $2 \times 2$ (dois sistemas de suplementação [0,5 e 1,0\% do PV ] e duas fontes de energia [grão de aveia e milho quebrado]), para avaliar o desempenho em pastagem de capim-marandu (Brachiaria brizantha Hochst ex. A. Rich Stapf), durante a estação seca. Os suplementos foram formulados para conter $15 \%$ de proteína bruta (PB). O ganho médio diário não diferiu entre os tratamentos ( 0,58 e 0,69 kg/dia para aveia e 0,54 e 0,66 kg/dia para milho, nos níveis 0,5 e 1,0\% do PV, respectivamente). Não houve diferença para rendimento de carcaça entre os tratamentos (média de 46,12\%). Observou-se elevada quantidade de massa de forragem de baixa qualidade, em decorrência, principalmente, de geadas ocorridas no período. Os valores médios para PB, fibra em detergente neutro (FDN) e fibra em detergente ácido (FDA) foram 5,34; 74,95 e 47,66, respectivamente. Grãos de aveia e grãos de milho apresentaram a mesma qualidade como suplemento para vacas de corte. Para uma situação com alta oferta de forragem, o nível de $0,5 \%$ no PV de milho mostrou maior retorno econômico.

Palavras-chave: aveia, desempenho animal, milho, rendimento de carcaça

\section{Energy Sources and Supplementation Level for Beef Cows Grazing Marandugrass (Brachiaria brizantha hochst ex. A. Rich stapf) During Winter}

\begin{abstract}
Fourty beef cows $(330 \mathrm{~kg})$ were allotted to a completely randomized design, in a $2 \times 2$ factorial scheme (two supplementation levesl [0.5 and $1.0 \% \mathrm{LW}$ ] and two energy sources [whole oat grain and ground corn grain]) to evaluate perfomance of animal grazing Marandugrass (Brachiaria brizantha Hochst ex. A. Rich Stapf), during the dry season. Supplements were formulated to contain $15 \%$ of crude protein $(\mathrm{CP})$. Average daily gain showed no difference among treatments $(0.58$ and $0.69 \mathrm{~kg} / \mathrm{d}$ for oat, and 0.54 and $0.66 \mathrm{~kg} / \mathrm{d}$ for corn, at levels of 0.5 and $1.0 \% \mathrm{LW}$, respectively). No difference was detected for carcass dressing among treatments, with average value of $46.12 \%$. Forage mass available was high, but quality was low, mainly as result of frost occurred in the period. Average values for CP, neutral detergent fiber (NDF) and acid detergent fiber (ADF) were 5.34, 74.95 and $47.66 \%$, respectively. Oat grain showed similar quality as corn for beef cow supplementation. Considering high forage mass in the pasture, $0.5 \% \mathrm{LW}$ supplementation showed higher economical efficiency.
\end{abstract}

Key Words: oat, animal performance, corn, carcass dressing

\section{Introdução}

A produção estacional de forrageiras nos países tropicais e subtropicais é fator limitante para rebanhos bovinos, com queda da produção de leite, redução da fertilidade, aumento da idade de abate, alcançando média nacional de 42-48 meses (Prado, 2000).

$\mathrm{Na}$ estação seca, as forragens apresentam desenvolvimento lento, com redução marcante nos teores de proteína e elevação nos teores de fibra pouco digestível e o consumo voluntário é reduzido
(Peruchena, 1999). A redução da qualidade da matéria seca ofertada é resultado de alterações nas proporções de folhas, colmo, inflorescência e material morto no perfil da pastagem.

Uma alternativa para a baixa produtividade e escassez de alimentos nas pastagens é a terminação de bovinos em confinamento, que, no entanto, tem custo elevado. Deve-se considerar que o problema não é apenas a terminação, mas também a falta de alimento para animais de sobreano, cria e matrizes.

\footnotetext{
${ }^{1}$ Parte da Dissertação de Mestrado do primeiro autor, apresentado ao Programa de Pós-Graduação em Zootecnia da Universidade Estadual de Maringá.

2Zootecnista, Msc. Fazenda Estrela d'Alva - Araruna-PR (re.zoo@zipmail.com.br).

3 Professores do Departamento de Zootecnia da UEM - Av. Colombo, 5790, CEP: 87.020-900, Maringá-PR (ccjobim@uem.br; afbranco@uem.br).Pesquisadores do CNPq.

${ }^{4}$ Aluno de Mestrado do PPZ - UEM (http://www.dzo.uem.br).
} 
A suplementação protéica e energética surge como alternativa para minimizar as perdas e alcançar ganhos satisfatórios no período seco. Segundo Curto et al. (1990), inúmeras pesquisas têm indicado que a suplementação protéica, em dietas à base de forragens de baixa qualidade, pode melhorar a produção de bovinos de corte.

O grão de aveia representa boa opção para suplementação de bovinos, uma vez que seu valor comercial em determinadas épocas do ano é bem menor que outros alimentos nobres. Porém, em virtude dos elevados teores de amido, quando fornecidos em grandes quantidades provoca redução do pH ruminal, alterando a composição bacteriana do rúmen, aumentando a população de bactérias amilolíticas e diminuindo as celulolíticas, com efeito negativo sobre a digestibilidade da parede celular e o consumo da forragem (Caton \& Dhuyvetter, 1997). Restle et al. (2001), testando diferentes processamentos do grão de aveia preta, encontraram diferença no ganho de peso e na conversão alimentar em vacas de descarte terminadas em confinamento. Para grão inteiro, o ganho foi de $0,776 \mathrm{~kg} / \mathrm{dia}$, enquanto para o grão moído, de $1,097 \mathrm{~kg} / \mathrm{dia}$, com conversão alimentar de 13,39 e 9,31 , respectivamente.

A casca de soja é outro importante resíduo agroindustrial que pode ser utilizada para formulação de suplementos para ruminantes. Em virtude do elevado teor de fibra e de nutrientes digestíveis totais (NDT) presentes no alimento, é bastante utilizada como fonte energética, pois essa fibra altamente digestível mantém a fermentação ruminal normal, não deprimindo microrganismos celulolíticos e evitando problemas de acidose (Ezequiel et al., 1999). A casca de soja contém, em média, 12,2\% de PB, $80 \%$ de NDT, $66,3 \%$ de fibra em detergente neutro (FDN) e 44,9\% de fibra em detergente ácido (FDA) (NRC, 1996). Semelhantemente à maioria dos subprodutos, a qualidade deste resíduo pode variar de acordo com os métodos do processamento, a origem ou variedade da soja e o grau de maturidade (Martin \& Hibberd, 1990).

O desempenho de vacas com predominância de sangue nelore terminadas em pastagens de capimmarandu (Brachiaria brizantha Hochst ex. A. Rich Stapf) foi avaliado em dois sistemas de suplementação, na estação da seca.

\section{Material e Métodos}

O experimento foi realizado na Fazenda Estrela d'Álva, situada no município de Araruna, noroeste do estado do Paraná, no período de junho de 2001 a setembro de 2001.

O clima da região é caracterizado como Cfa segundo a classificação de Köeppen e o solo é classificado como latossolo vermelho escuro, textura média.

A pastagem de capim-marandu foi estabelecida em outubro de 2000 em uma área de 19 ha, dividida em quatro piquetes de 4,7 ha utilizando-se cerca elétrica de dois fios. No mês de março de 2001, a pastagem foi vedada até a entrada dos animais, em junho de 2001. A água foi fornecida em bebedouros com bóia e os suplementos, em cochos de plástico.

Foram utilizadas 40 vacas com predominância de sangue Nelore (aproximadamente 5 anos de idade e peso médio inicial de $330 \mathrm{~kg}$ ). Antes do início do experimento, os animais permaneceram em período de adaptação de 20 dias, quando foram vermifugados.

Para reduzir a influência da possível variação na disponibilidade de forragem entre piquetes, os animais foram rotacionados em sentido preestabelecido, a cada 15 dias. Foram pesados no início do período experimental e a cada 28 dias, totalizando quatro pesagens até o término da avaliação.

Os animais (dez vacas por tratamento) foram distribuídos em quatro tratamentos, constituídos de duas fontes energéticas à base de grãos de aveia preta (Avena strigosa Shereb) ou milho (Zea mays L.), em dois níveis de suplementação $(0,5$ e 1,0\% PV).

$\mathrm{Na}$ Tabela 1, são apresentadas as composições centesimal e química das rações experimentais, formuladas à base de grãos de aveia preta e grãos de milho, para conter $15 \%$ de PB e cerca de $80 \%$ de NDT.

Durante o período experimental (84 dias), a disponibilidade de forragem ( $\mathrm{kg}$ MS/ha) e a oferta de massa de forragem (kg MS/100 kg PV) foram estimadas pelo método da dupla amostragem (Wilm et al., 1994), nas seguintes datas: 22/06, 20/07, 17/08 e 14/09. Foram coletadas quatro amostras em cada piquete, cortadas rente ao solo, pesadas e secas em estufas com ventilação forçada a $65^{\circ} \mathrm{C}$, durante 72 horas. Utilizando-se os valores das amostras cortadas e estimadas visualmente, foi calculada a massa de forragem, em $\mathrm{kg}$ de $\mathrm{MS} / \mathrm{ha}$, segundo a equação proposta por Gardner (1986): 
Tabela 1 - Composição centesimal e química das rações experimentais

Table 1 - Centesimal and chemical composition of the experimental rations

\begin{tabular}{|c|c|c|}
\hline \multirow[b]{2}{*}{$\begin{array}{l}\text { Ingrediente } \\
\text { Ingredient }\end{array}$} & \multicolumn{2}{|c|}{$\begin{array}{l}\text { Suplemento } \\
\text { Supplement }\end{array}$} \\
\hline & $\begin{array}{l}\text { Ração milho }(\mathrm{kg}) \\
\text { Corn ration }(\mathrm{kg})\end{array}$ & $\begin{array}{c}\text { Ração aveia }(\mathrm{kg}) \\
\text { Oat ration }(\mathrm{kg})\end{array}$ \\
\hline Aveia & 0,00 & 63,00 \\
\hline $\begin{array}{l}\text { Oat } \\
\text { Milho grão } \\
\text { Corn grain }\end{array}$ & 61,70 & 0,00 \\
\hline $\begin{array}{l}\text { Casca de soja } \\
\text { Soybean hulls }\end{array}$ & 33,00 & 33,00 \\
\hline $\begin{array}{l}\text { Uréia } \\
\text { Urea }\end{array}$ & 2,10 & 1,10 \\
\hline $\begin{array}{l}\text { Calcário } \\
\text { Limestone }\end{array}$ & 0,30 & 0,37 \\
\hline $\begin{array}{l}\text { Fosfato bicálcico } \\
\text { Dicalcium phosphate }\end{array}$ & 0,40 & 0,08 \\
\hline $\begin{array}{l}\text { Fospec } 65^{1} \\
\text { Fospec } 65\end{array}$ & 2,50 & 2,50 \\
\hline & 100,00 & 100,00 \\
\hline $\begin{array}{l}\text { Nutrientes } \\
\text { Nutrients } \\
\end{array}$ & & \\
\hline $\begin{array}{l}\mathrm{PB}(\%) \\
C P(\%)\end{array}$ & 15,0 & 15,2 \\
\hline $\begin{array}{l}\operatorname{PDR}^{2}(\% \mathrm{~PB}) \\
D R P(\% C P)\end{array}$ & 55,2 & 69,4 \\
\hline $\begin{array}{l}\text { NDT }(\%) \\
T D N(\%)\end{array}$ & 80,7 & 75,9 \\
\hline $\mathrm{Ca}(\%)$ & 0,7 & 0,7 \\
\hline $\mathrm{P}(\%)$ & 0,48 & 0,49 \\
\hline
\end{tabular}

${ }_{1}^{1}$ Sal mineral comercial.

1 Comercial mineral salt.

2 Proteína degradada no rúmen.

2 Degradable rumen protein.

$$
\mathrm{MF}=\mathrm{X}+\mathrm{b}\left(\mathrm{Y}-\mathrm{Y}^{\natural}\right),
$$

em que MF = massa de forragem em $\mathrm{kg}$ de MS/ha; $\mathrm{X}=$ média das amostras cortadas; $\mathrm{b}=$ coeficiente de regressão entre as amostras cortadas e estimadas visualmente; $\mathrm{Y}=$ média das amostras estimadas visualmente; $Y^{`}=$ média das amostras estimadas visualmente e depois cortadas.

A taxa de lotação (TL) foi calculada considerando-se unidade animal (UA) de $450 \mathrm{~kg}$ de PV, utilizando-se a seguinte fórmula:

$$
\mathrm{TL}=\mathrm{UAt} / \text { Área, }
$$

em que $\mathrm{TL}=$ taxa de lotação $(\mathrm{UA} / \mathrm{ha}) ; \mathrm{UAt}=$ unidade animal total; Área = área experimental total (ha).
O cálculo da oferta de forragem (OF) foi efetuado segundo o conceito de Heringer \& Carvalho (2002), em que a oferta de forragem representa determinada quantidade de forragem ( $\mathrm{kg}$ de MS) ofertada ao animal (para cada $100 \mathrm{~kg}$ de PV) por determinado período de tempo (dia).

O delineamento experimental adotado foi inteiramente casualizado com quatro tratamentos e 10 repetições, segundo o modelo $Y_{i j}=m+D_{i}+e_{i j}$, em que $\mathrm{Y}_{\mathrm{ij}}$ é o valor observado do animal que recebeu a dieta i; $\mathrm{m}$, constante geral; D, efeito da dieta $\mathrm{i}$, sendo $\mathrm{i}=1,2,3$ e 4; e $\mathrm{e}_{\mathrm{ij}}$, erro aleatório associado a cada observação. Os dados de desempenho animal foram submetidos à análise de variância e as médias, comparadas pelo teste Tukey (5\%).

\section{Resultados e Discussão}

As médias da composição química dos alimentos constituintes do suplemento e do capim-marandu durante o período experimental são apresentadas na Tabela 2. Os grãos de aveia preta apresentaram teor de PB elevado, chegando a atingir valor 4,8\% superior aos grãos de milho. As frações FDN e FDA nos grãos de aveia apresentam valores bastante superiores aos grãos de milho, atingindo 14,6e 9,6 pontos percentuais, respectivamente, qualificando os grãos de aveia preta como um bom alimento para ser utilizado em suplementos destinados a animais em pastejo.

O teor de PB do capim-marandu (Tabela 2) nesse período é baixo, inferior ao valor mínimo (7,0\%) mencionado por Moore \& Kunkle (1998) para não reduzir o consumo. A fração fibra também foi bastante elevada, em decorrência da idade avançada da planta. As plantas apresentam acúmulo de MS na maturação, em razão da menor proporção de folhas e aumento de colmos e material morto. Aumento na produção, com o avanço da idade, em função do período, pode acarretar diminuição na produção animal, graças ao menor valor nutricional de caule em relação a lâminas e à redução na porcentagem de PB e na digestibilidade da MS.

Avaliando a composição química do capimmarandu em diferentes idades de corte, Gerdes et al. (1999) obtiveram porcentagem de PB média de 13,9 e FDN de 68,9 na época das águas, quando a produção de forragem é de melhor qualidade. No entanto, com a maturação da gramínea e a falta de chuvas no período do inverno, o teor de PB decresce e aumenta o teor de FDN. 
Tabela 2 - Composição química média dos ingredientes do suplemento e da massa de forragem disponível no período de junho a setembro de 2001

Table 2 - Average chemical composition of the ingredients of supplement and available forage mass from June to September 2001

\begin{tabular}{|c|c|c|c|c|c|c|}
\hline & $\begin{array}{l}\operatorname{MS}(\%) \\
D M(\%)\end{array}$ & $\begin{array}{l}\mathrm{PB}(\%) \\
C P(\%)\end{array}$ & $\begin{array}{l}\mathrm{FDN}(\%) \\
N D F(\%)\end{array}$ & $\begin{array}{l}\mathrm{FDA}(\%) \\
A D F(\%)\end{array}$ & $\begin{array}{l}\mathrm{MO}(\%) \\
O M(\%)\end{array}$ & $\begin{array}{c}\operatorname{MM}^{1}(\%) \\
M M^{1}(\%)\end{array}$ \\
\hline $\begin{array}{l}\text { Grãos de aveia } \\
\text { Oat grain }\end{array}$ & 91,9 & 14,9 & 30,4 & 13,8 & 89,5 & 2,4 \\
\hline $\begin{array}{l}\text { Grãos de milho } \\
\text { Corn grain }\end{array}$ & 89,5 & 10,1 & 15,8 & 4,2 & 87,3 & 2,2 \\
\hline $\begin{array}{l}\text { Casca de soja } \\
\text { Soybean hulls }\end{array}$ & 92,2 & 10,8 & 66,3 & 52,6 & 76,3 & 15,9 \\
\hline $\begin{array}{l}\text { Capim-marandu } \\
\text { Marandugrass }\end{array}$ & 94,6 & 5,3 & 74,9 & 46,2 & 89,6 & 5,0 \\
\hline
\end{tabular}

${ }^{1}$ Matéria mineral (Mineral matter).

Aproximadamente 90 dias antes do início do experimento, os piquetes foram vedados, a fim de garantir boa disponibilidade inicial de forragem aos animais e, por essa razão, verificou-se grande quantidade de MS/ha e de lâmina foliar/ha. A massa de forragem disponível declinou até o mês de agosto, retornando ao período de crescimento em setembro, com o aumento da produção de lâmina foliar (LF).

Em condições de subpastejo, a forragem selecionada apresenta baixa qualidade nutricional, em razão do alongamento do caule, do avanço do estádio fenológico das espécies e da reduzida ou ausente capacidade de rebrote das plantas (Maraschin, 1994).

$\mathrm{Na}$ Tabela 3, são apresentadas as médias das disponibilidade de massa de forragem, disponibilidade das frações lâmina foliar (LF), colmo (C), material morto (MM) e a relação lâmina foliar/colmo (LF/C), valores para oferta de forragem (OF), oferta de lâmina foliar (OL) e taxa de lotação (TL) da pastagem de capim-marandu no inverno.

Com o diferimento, os pastos de capim-marandu apresentaram quantidade de forragem disponível suficiente para manter carga animal em torno de $750 \mathrm{~kg}$ de peso vivo/ha, no período em que normalmente na região noroeste do Paraná, assim como outras regiões tropicais, a escassez de forragem é mais crítica. As cargas animal para os períodos de 22/06, 20/07, 17/08 e 14/09/01 foram de 693, 747, 778,5 e $801 \mathrm{~kg}$ de peso vivo/ha, respectivamente.

Quanto à distribuição das frações da planta, a produção de MS de folhas foi maior no início do experimento em junho/2001 (1.138 kg/ha), diminuindo com o avanço da idade e atingindo $315 \mathrm{~kg} / \mathrm{ha}$ em agosto/2001. A quantidade disponível de LF apresentou redução de $573 \mathrm{~kg}$ de MS/ha no mês de julho em relação a junho, em decorrência do início do pastejo e do comportamento seletivo dos animais. Outro valor reduzido de $\mathrm{LF}$ ( $250 \mathrm{~kg}$ de MS/ha) foi obtido entre os meses de julho a agosto, em virtude do consumo e da ocorrência de geadas. Com condições climáticas favoráveis, a partir de setembro o capim-marandu iniciou a rebrota, evidenciada pelo acréscimo na produção de LF, chegando a superar a produção de agosto em $420 \mathrm{~kg}$ de MS/ha. Segundo Alberto (1997), o rendimento de folhas e a densidade do material verde são os principais fatores que influenciam o consumo dos animais em pastejo.

A fração colmo (C) atingiu proporções mais elevadas (em torno de $1.046 \mathrm{~kg} / \mathrm{ha}$ ), observando-se o menor valor no último período, provavelmente em razão da alta taxa de lotação empregada. As diferenças na relação LF/C ocasionaram diferenças sobretudo na qualidade da matéria seca, na densidade e no consumo de forragem. A relação LF/C iniciou-se com 1,09, decresceu com o avanço da idade e aumentou no mês de setembro, graças ao vigor da rebrota. Segundo Bortolo et al. (2001), quanto maior a relação LF/C, melhor será o valor nutritivo da planta forrageira, pois os bovinos selecionam preferencialmente a lâmina foliar. Euclides et al. (1992) verificaram que a dieta selecionada pelos animais em pastagem de capim-braquiária apresentou $90 \%$ de forragem verde, com grande participação da fração lâmina foliar.

Zimmer et al. (1995) observaram, para diversas espécies do gênero Brachiaria, menor proporção da relação folha/colmo no período das secas. A porcentagem de folhas está relacionada com o peso e idade dos perfilhos, posto que perfilhos mais velhose desenvolvidos possuem menor porcentagem de folhas, diminuindo a relação folha/colmo com o avanço da idade da rebrota. 
Tabela 3 - Disponibilidade média de massa de forragem, disponibilidade das frações lâmina foliar (LF), colmo (C), material morto (MM), relação lâmina foliar/colmo (LF/C), valores para oferta de forragem (OF), oferta de lâmina foliar (OL) e taxa de lotação (TL), em pastos de Brachiaria brizantha cv. Marandu no inverno

Table 3 - Average availability of forage mass, availability of leaf blade (LB), stem (S), dead material (DM), leaf blade/stem ratio $(L B / S)$, values to forage offer $(F O)$ and leaf blade offer $(B O)$ and stocking rate $(L T)$ in Brachiaria brizantha pasture during winter

\begin{tabular}{|c|c|c|c|c|c|}
\hline \multirow[t]{2}{*}{$\begin{array}{l}\text { Variáveis } \\
\text { Variables }\end{array}$} & \multicolumn{4}{|c|}{$\begin{array}{l}\text { Data } \\
\text { Date }\end{array}$} & \multirow[t]{2}{*}{$\begin{array}{l}\text { Média } \\
\text { Mean }\end{array}$} \\
\hline & $\begin{array}{l}22 / 06 / 01 \\
06 / 22 / 01\end{array}$ & $\begin{array}{l}20 / 07 / 01 \\
07 / 20 / 01\end{array}$ & $\begin{array}{l}17 / 08 / 01 \\
08 / 17 / 01\end{array}$ & $\begin{array}{l}14 / 09 / 01 \\
09 / 14 / 01\end{array}$ & \\
\hline $\begin{array}{l}\text { MS/ha }(\mathrm{kg}) \\
D M / h a(k g)\end{array}$ & 3955,90 & 3401,60 & 2785,20 & 2989,08 & 3282,90 \\
\hline $\begin{array}{l}\mathrm{LF} / \mathrm{ha}(\mathrm{kg}) \\
L B / \mathrm{ha}(\mathrm{kg})\end{array}$ & 1137,75 & 565,02 & 315,10 & 735,10 & 688,20 \\
\hline $\begin{array}{l}\text { C/ha (kg) } \\
\text { S/ha }(\mathrm{kg})\end{array}$ & 1045,92 & 1200,02 & 890,03 & 830,30 & 991,50 \\
\hline $\begin{array}{l}\mathrm{LF} / \mathrm{C}(\mathrm{kg}) \\
L B / S(\mathrm{~kg})\end{array}$ & 1,09 & 0,47 & 0,35 & 0,88 & 0,69 \\
\hline $\begin{array}{l}\mathrm{MM}^{1} / \mathrm{ha}(\mathrm{kg}) \\
D M / h a(k g)\end{array}$ & 1767,86 & 1636,60 & 1580,41 & 1424,03 & 1607,20 \\
\hline $\begin{array}{l}\mathrm{OF}(\mathrm{kg} \mathrm{MS} / 100 \mathrm{~kg} \mathrm{PV}) \\
F O(\mathrm{~kg} D M / 100 \mathrm{~kg} B W)\end{array}$ & 20,17 & 16,03 & 12,63 & 13,16 & 15,50 \\
\hline $\begin{array}{l}\text { OL (kg MS/100 kg PV) } \\
B O(\mathrm{~kg} D M / 100 \mathrm{~kg} \mathrm{BW})\end{array}$ & 5,80 & 2,66 & 1,43 & 3,24 & 3,28 \\
\hline $\begin{array}{l}\text { TL (UA/ha) } \\
S R(A U / h a)\end{array}$ & 1,54 & 1,66 & 1,73 & 1,78 & 1,68 \\
\hline
\end{tabular}

$\mathrm{UA}=$ unidade animal $=450 \mathrm{~kg} P \mathrm{PV}(A U=$ animal unity $=450 \mathrm{~kg} \mathrm{BW})$.

1 = material morto (dead matter).

O material morto (MM) foi constituído de folhas mortas/senescentes ligadas ao colmo, acima da altura de corte. A grande quantidade de MM pode ser atribuída ao acúmulo de forragem durante o período em que o pasto permaneceu vedado e também às condições climáticas adversas. O material morto do pasto foi semelhante $(\mathrm{P}>0,05)$ nos diferentes períodos, apresentando o menor valor no quarto período $(1.424 \mathrm{~kg} / \mathrm{ha})$ e o maior no primeiro $(1.768 \mathrm{~kg} / \mathrm{ha})$. A maior proporção de material morto em relação às frações verdes da planta foram decorreram, em parte, das condições de meio ambiente (déficit hídrico e temperaturas amenas) predominantes no período experimental e da ocorrência de geadas no início do experimento.

A produção de massa seca de material morto correspondem, em média, 40 a $50 \%$ da produção total, evidenciando que grande quantidade de massa de forragem disponível não foi consumida pelos animais. Euclides et al. $(1999,2000)$ detectaram correlações positivas entre consumo e disponibilidade de massa verde e de folhas, e negativas entre as porcentagens de material morto presente em pastagens de Panicum e Brachiaria. Resultados semelhantes foram observados por Cecato et al. (2000), ao avaliarem perdas de forragem em capim-tanzânia. Infere-se, portanto, que grande parte da forragem produzida no sistema pode retornar ao ecossistema através da reciclagem de nutrientes, favorecendo a melhoria da estrutura do solo e crescimento da planta.

A disponibilidade média de forragem verde (colmos + lâminas) durante o período experimental foi de $1680 \mathrm{~kg}$ de MS/ha, com produção média de $41 \%$ de lâminas foliares, em conseqüência da alta oferta inicial das frações LF + C (2184 kg/ha) e da baixa lotação (1,54 UA/ha). Mesmo com alta oferta de forragem a qualidade foi baixa, principalmente por causa das geadas, com teores médios de PB, FDN e FDA de 5,34; 60,0 e 47,66\%, respectivamente.

A oferta média de forragem foi de $15,50 \mathrm{~kg} \mathrm{MS} /$ $100 \mathrm{~kg}$ PV. O menor valor da oferta foi observado em 17/08/2001 (12,63 kg MS/100 kg PV), decorrente da elevada TL imposta (1,73 UA/ha) e da falta de chuvas, diminuindo a proporção de lâminas verdes + colmo e, conseqüentemente, aumentando a de material morto da forragem.

Gomide et al. (2001), em experimento realizado com Brachiaria decumbens, com oferta de pasto a 4 e $8 \%$ PV, não encontraram efeito das ofertas sobre 
o teor de PB de frações da planta, embora se tenha observado tendência de maiores teores de PB em plantas submetidas a menores ofertas, graças à rebrota de melhor qualidade, caracterizada por volume de folhas verdes e tenras. Os piquetes submetidos a maior oferta acumularam maior quantidade de folhas velhas, contribuindo para o menor teor de PB.

Constatou-se que, inicialmente, a OL foi alta, inclusive superior à capacidade de consumo diário das vacas, ao passo que, no mês de agosto, declinou, o que pode ter influenciado o consumo de frações menos digestíveis das plantas.

A taxa de lotação aumentou em função do ganho de peso dos animais. O valor médio de 1,68 UA/ha foi semelhante ao valor encontrado por Euclides et al. (2001) para o capim-marandu (1,5 UA/ha), no período seco. A taxa de lotação diária influi na utilização do pasto e na persistência do relvado, apresentando grande efeito na produção animal, por determinar a quantidade, a qualidade e a composição botânica da forragem disponível.

Em consequência da grande quantidade de forragem normalmente produzida durante o período primavera-verão, as pastagens comportam elevado número de animais nas águas, que é reduzido durante a seca, graças à escassez de forragem.

Na Tabela 4, são apresentados os dados de ganho médio diário e rendimento de carcaça de vacas em pastagem de capim-marandu, durante a época seca. O desempenho animal em relação ao ganho médio diário (GMD) foi semelhante entre os tratamentos $(\mathrm{P}>0,05)$. Entretanto, os tratamentos com suplemento de $1,0 \%$ do PV foram superiores em $19,0 \%$ e $22,2 \%$ em relação ao suplemento com $0,5 \%$ do $\mathrm{PV}$, respectivamente, para a fonte de energia grãos de aveia e milho. O rendimento de carcaça (RC) também não apresentou diferença $(\mathrm{P}>0,05)$ entre tratamentos, com valor médio de $46,12 \%$.

A análise para tratamento dentro de período mostrou que, inicialmente, os animais apresentaram elevados ganhos de peso, explicados, em parte, pelo ganho compensatório, uma vez que, antes do início do período experimental, esses animais não recebiam suplementação e encontravam-se em pastos com baixa qualidade de forragem, apresentando visível perda de peso.

O menor GMD nos meses de agosto e setembro pode ser atribuído, em parte, à redução na qualidade da massa de forragem disponível, em decorrência de geadas que atingiram a região no final do mês de julho, quando se constatou aumento dos valores de NDT e a DIVMO (de 54,79 para $51,88 \%$ e de 50,27 para $46,91 \%$, do mês de julho para setembro, respectivamente), resultando em menor GMD das vacas nos quatro tratamentos.

A suplementação em pastagem provoca a substituição do consumo de forragem da pastagem pelo suplemento, proporcionando aumento na carga animal suportada pela pastagem e, conseqüentemente, na terminação de maior número de animais em uma

Tabela 4- Ganho médio diário $(\mathrm{kg})$ e rendimento de carcaça de vacas em pastagem de capim-marandu, em níveis de suplementação, durante a época seca

Table 4 - Average daily gain (kg)and carcass yield for cows in Marandugrass pasture, in suplementation levels, during winter

\begin{tabular}{|c|c|c|c|c|c|}
\hline \multirow[t]{2}{*}{$\begin{array}{l}\text { Tratamento } \\
\text { Treatment }\end{array}$} & \multicolumn{3}{|c|}{$\begin{array}{l}\text { Períodos } \\
\text { Periods }\end{array}$} & \multirow[b]{2}{*}{$\begin{array}{c}\mathrm{GMD}(\mathrm{kg}) \\
M D G\end{array}$} & \multirow[b]{2}{*}{$\begin{array}{l}\mathrm{RC}^{1}(\% \\
\quad C R\end{array}$} \\
\hline & $\begin{array}{l}20 / 07 \\
07 / 20\end{array}$ & $\begin{array}{l}17 / 08 \\
08 / 17\end{array}$ & $\begin{array}{l}14 / 09 \\
09 / 14\end{array}$ & & \\
\hline $\begin{array}{l}\text { Aveia } 0,5 \% \text { PV } \\
\text { Oat } .5 \% B W\end{array}$ & $0,96 \mathrm{aA}$ & $0,58 \mathrm{aB}$ & $0,20 \mathrm{bC}$ & $0,57 \mathrm{a}$ & $44,85 a$ \\
\hline $\begin{array}{l}\text { Aveia } 1,0 \% \mathrm{PV} \\
\text { Oat } 1.0 \% B W\end{array}$ & $1,05 \mathrm{aA}$ & $0,52 \mathrm{aB}$ & $0,50 \mathrm{aB}$ & $0,69 a$ & $46,09 a$ \\
\hline $\begin{array}{l}\text { Milho 0,5\% PV } \\
\text { Corn .5\% BW }\end{array}$ & $0,76 \mathrm{aA}$ & $0,50 \mathrm{aB}$ & $0,37 \mathrm{aB}$ & $0,54 a$ & $46,42 \mathrm{a}$ \\
\hline $\begin{array}{l}\text { Milho 1,0\% PV } \\
\text { Corn 1.0\% BW }\end{array}$ & $1,00 \mathrm{aA}$ & $0,51 \mathrm{aB}$ & $0,47 \mathrm{aB}$ & $0,66 \mathrm{a}$ & $47,11 \mathrm{a}$ \\
\hline CV $(\%)$ & 20,31 & 14,24 & 18,47 & 29,3 & 11,26 \\
\hline
\end{tabular}

Médias nas linhas seguidas de letras maiúsculas e nas colunas seguidas de letras minúsculas iguais não diferiram pelo teste Tukey a $5 \%$ de propabilidade.

Mean in lines with the same capital letter and in columns with the same lowen case do not difere by Tukey testa $t 5 \%$ significance.

${ }^{1} \mathrm{RC}=$ rendimento de carcaça.

${ }^{1} C R=$ carcass yield .

\section{R. Bras. Zootec., v.34, n.1, p.151-158, 2005}


mesma área. O efeito substitutivo do consumo de forragem pelo suplemento, mesmo sem adição no GMD, é desejável em situações com oscilações no crescimento da forrageira e com carga animal fixa na área da pastagem.

Elevados GMD $(0,960 \mathrm{~kg} /$ dia $)$ também foram observados por Macedo \& Silva (1999), que suplementaram novilhas Nelore em pastagens de Brachiaria brizantha cv. MG4, com disponibilidade de $2540 \mathrm{~kg}$ de MS/ha e suplemento contendo $24 \%$ de $\mathrm{PB}$ a $0,8 \%$ do PV, entre setembro e novembro.

A quantidade de forragem ofertada aos animais durante o período experimental pode ser considerada adequada, pois, além de permitir ganhos individuais elevados (Tabela 4), proporcionou ganhos de peso vivo por área de 101,98; 123,45; 96,62 e 118,08 kg/ha para os respectivos tratamentos de 0,5 e $1,0 \%$ PV de aveia e 0,5 e $1,0 \%$ PV de milho. Lourenço \& Leme (1999), em estudos com taxa de lotação de 1,7 cab./ha, em uma pastagem exclusiva de Brachiaria brizantha na época da seca, registraram ganhos de $0,498 \mathrm{~kg} /$ anim./dia e $77 \mathrm{~kg} / \mathrm{ha}$, enquanto para a pastagem de Brachiaria brizantha com suplemento durante a seca $(67,5 \%$ NDT e $46,42 \%$ PB), ganhos de $0,700 \mathrm{~kg} /$ anim/dia e $109 \mathrm{~kg} / \mathrm{ha}$.

Para a análise de custos, não se consideraram os custos fixos e de mão-de-obra, uma vez que seriam iguais para todos os tratamentos; além disso, objetivou-se avaliar o beneficio do uso dos grãos de milho ou de aveia em diferentes níveis de suplementação. Embora os tratamentos com maior nível de suplementação tenham resultado em melhores ganhos de peso, a análise de custos indicou o melhor retorno para suplementação de $0,5 \%$ do PV, destacando-se o uso de milho, que resultou em menor custo/@ produzida e, conseqüentemente, maior lucro.

Na Tabela 5, são apresentados os valores referentes à análise de custos, em função dos tratamentos.

Como a produção de carcaça (@) foi semelhante entre os tratamentos, o custo de produção/@ foi determinante para o lucro. Dessa forma, o custo de produção/@ na suplementação à base de grãos de aveia a $0,5 \% \mathrm{PV}$ foi $\mathrm{R} \$ 0,50$ (cinqüenta centavos) maior que o suplemento à base de milho no mesmo nível.

Ressalta-se que, com elevado custo do suplemento, o nível de suplementação elevado pode ser determinante na viabilidade econômica. Constata-se, por exemplo, que a suplementação à base de milho a 1,0\% PV resultou em retorno (lucro/@) 96,5\% inferior ao nível de $0,5 \% \mathrm{PV}$.

\section{Conclusões}

O diferimento do capim-marandu para uso no inverno, em uma situação de oferta de lâmina foliar média de 3,0\% do peso vivo, possibilita bom desempenho de vacas adultas suplementadas.

Os grãos de aveia preta apresentam qualidade similar à de grãos de milho na suplementação de fêmeas adultas, proporcionando ganho de peso satisfatório.

Para uma situação com elevada oferta de forragem, o nível de suplementação de milho a $0,5 \%$ do peso vivo de suplemento à base de milho resulta em menor custo/animal/dia.

Tabela 5 - Desempenho de vacas suplementadas no período de inverno em pastagens de capim-marandu e custos da suplementação

Table 5 - Performance of supplemented cows in the winter period in Marandugrass pasture and supplementation cost

\begin{tabular}{|c|c|c|c|c|c|c|}
\hline $\begin{array}{l}\text { Tratamento } \\
\text { Treatment }\end{array}$ & $\begin{array}{l}\text { Custo/Animal }(\mathrm{R} \$) \\
\text { Cost/Animal }(R \$)\end{array}$ & $\begin{array}{c}\text { Custo suplemento/ } \\
\text { animal/dia } \\
\text { Suplement cost/ } \\
\text { Animal/day }\end{array}$ & $\begin{array}{l}\text { Carcaça(@) } \\
\text { Cancass (@) }\end{array}$ & $\begin{array}{c}\text { Custo/@ } \\
\text { Cost/@ }\end{array}$ & $\begin{array}{c}\operatorname{Receita}^{1}(\mathrm{R} \$) \\
\text { Income }(\mathrm{R} \$)\end{array}$ & $\begin{array}{r}\text { Lucro/@ }(\mathrm{R} \$) \\
\text { Profit/@ }(R \$)\end{array}$ \\
\hline $\begin{array}{l}\text { Aveia }(0,5 \% \mathrm{PV}) \\
\text { Oat }(.5 \% \mathrm{BW})\end{array}$ & 360,00 & 0,28 & 11,5 & 33,37 & 437,00 & 4,63 \\
\hline $\begin{array}{l}\text { Aveia }(1,0 \% \mathrm{PV}) \\
\text { Oat }(1.0 \% \mathrm{BW})\end{array}$ & 360,00 & 0,57 & 12,0 & 33,97 & 456,00 & 4,03 \\
\hline $\begin{array}{l}\text { Milho }(0,5 \% \mathrm{PV}) \\
\text { Corn }(.5 \% \mathrm{BW})\end{array}$ & 360,00 & 0,29 & 11,7 & 32,87 & 444,60 & 5,13 \\
\hline $\begin{array}{l}\text { Milho }(1,0 \% \mathrm{PV}) \\
\text { Corn }(1.0 \% \mathrm{BW})\end{array}$ & 360,00 & 0,60 & 11,5 & 35,39 & 437,00 & 2,61 \\
\hline
\end{tabular}

$1=$ Valor da @ em setembro/2001 = R \$38,00 (Cotação dólar, 1U\$ = R\$2,605).

$1=$ Value of @in 2001/September $=R \$ 38.0$.

R. Bras. Zootec., v.34, n.1, p.151-158, 2005 


\section{Literatura Citada}

ALBERTO, E. Efectos de la calidad de los forrajes y la suplementacion en el desempeño de ruminantes en pastoreo (con especial referencia a vacas lecheras). In: SIMPÓSIO SOBRE AVALIAÇÃO DE PASTAGENS COM ANIMAIS, 1997, Maringá. Anais... Maringá: Universidade Estadual de Maringá, 1997. p.149.

BORTOLO, M.; CECATO, U.; MARTINS, E.N. et al. Avaliação de uma pastagem de coastcross-1 (Cynodon dactylon (L.) Pers) sob diferentes níveis de matéria seca residual. Revista Brasileira de Zootecnia, v.30, n.3, p.627-635, 2001.

CATON, J.S.; DHUYVETTER, D.V. Influence of energy supplementation on grazing ruminants: requirements and responses. Journal of Animal Science, v.75, p.533-542, 1997.

CECATO, U.; YANAKA, F.Y.; TOSCANO, M.R.B.F. et al. Influência da adubação nitrogenada e fosfatada na produção, na rebrota e no perfilhamento do capim-marandu (Brachiaria brizantha Hochst. Stapf. cv. Marandu), Acta Scientiarum, v.22, n.3, p.817-822, 2000.

CURTO, T.; COCHRAN, R.C.; CORAH, L.R. et al. Supplementation of dormant tallgrass-prairie forage: II performance and forage utilization characteristics in grazing beef cattle receiving supplements of different protein concentrations. Journal of Animal Science, v.68, p.532-542, 1990.

EUCLIDES, V.P.B.; MACEDO, M.C.M.; OLIVEIRA, M.P. Avaliação de diferentes métodos de amostragem para se estimar o valor nutritivo de forragens sob pastejo. Revista Brasileira de Zootecnia, v.21, p.691-702, 1992.

EUCLIDES, V.P.B.; MACEDO, M.C.M.; OLIVEIRA, M.P. Avaliação de cultivares de Panicum maximum em pastejo. In: REUNIÃO ANUAL DA SOCIEDADE BRASILEIRA DE ZOOTECNIA, 36., 1999, Porto Alegre. Anais... São Paulo: 1999 SBZ/Videolar, CD-ROM. FOR-020.

EUCLIDES, V.P.B.; MACEDO, M.C.M.; VALÉRIO, J.R. et al. Cultivar Massai (Panicum maximum) uma nova opção forrageira: características de adaptação e produtividade. In: REUNIÃO ANUAL DA SOCIEDADE BRASILEIRA DE ZOOTECNIA, 37., 2000, Viçosa, MG. Anais... Viçosa: SBZ/ São Paulo: Videolar, CD-ROM. Oral. Forragicultura. 0691.

EUCLIDES, V.P.B.; EUCLIDES FILHO, K.; COSTA, F.P. et al. Desempenho de novilhos F1s Angus-Nelore em pastagens de Bachiaria decumbens submetidos a diferentes regimes alimentares. Revista Brasileira de Zootecnia, v.30, n.2, p.451-462, 2001.

EZEQUIEL, J.M.B.; MENDES, A.R.; SILVA, L.D.F. et al. Estimativa da digestibilidade através da FDN indigestível de rações contendo dois níveis de casca de soja e diferentes fontes protéicas em novilhos mestiços. In: REUNIÃO ANUAL DA SOCIEDADE BRASILEIRA DE ZOOTECNIA, 36., 1999, Porto Alegre. Anais...Porto Alegre: SBZ, CD ROOM, NUR-130.

GARDNER, A.L. Técnicas de pesquisa em pastagens e aplicabilidade de resultados em sistemas de produção. Brasília: IICA/EMBRAPA-CNPGL, 1986. 197p (Série publicações miscelâneas, 634).

GERDES, L.; WERNER, J.C.; COLOZZA, M.T. Composição química dos capins marandu, setária e tanzânia em diferentes idades de corte. In: REUNIÃO ANUAL DA SOCIEDADE BRASILEIRA DE ZOOTECNIA, 1999, Porto Alegre. Anais... Porto Alegre: Sociedade Brasileira de Zootecnia, 1999.

R. Bras. Zootec., v.34, n.1, p.151-158, 2005
GOMIDE, J.A.; WENDLING, I.J.; BRAS, S.P. et al. Consumo e produção de leite de vacas maetiças em pastagem de Brachiaria decumbens manejada sob duas ofertas diárias de forragem. Revista Brasileira de Zootecnia, v.30, n.4, p.11941199, 2001.

HERINGER, G.; CARVALHO, P.C.F. Ajuste da carga animal em experimento de pastejo: uma nova proposta. Ciencia Rural, Santa Maria. v.32, n.4, p.675-679, 2002.

LOURENÇO, A.J.; LEME, P.R. Desempenho animal em pastagem de Brachiaria brizantha associado a banco de proteína ou suplementação alimentar. In: REUNIÃO ANUAL DA SOCIEDADE BRASILEIRA DE ZOOTECNIA, 36., 1999, Porto Alegre. Anais... Porto Alegre, 1999.

MACEDO, M.P.; Da SILVA, M.V.G.B. Efeito da suplementação no desempenho de novilhas de corte em pastagens na época da seca. In: REUNIÃO ANUAL DA SOCIEDADE BRASILEIRA DE ZOOTECNIA, 36., 1999, Porto Alegre. Anais...Porto Alegre: Sociedade Brasileira de Zootecnia, CD-ROOM, NUR-13.

MARASCHIN, G.E. Sistemas de pastejo. In: PEIXOTO, A.M.; MOURA, J.L.; FARIA, V.P. (Eds.) Pastagens. Fundamentos da exploração racional. 2.ed. Piracicaba: Fundação de Estudos Agrários Luiz de Queiroz, 1994. p.337-376.

MARTIN, S.K.; HIBBERD, C.A. Intake and digestibility of low-quality native grass hay by beef cows supplemented with graded levels of soybean hulls. Journal of Animal Science, v.68, p.4319-25, 1990.

MOORE, J.E.; KUNKLE, W.E. Balancing protein and energy in forages. In: FLORIDA BEEF CATTLE SHORT COURSE, 1998, Gainesville. Proceedings... Gainesville: University of Florida, 1998. p.119-126.

NATIONAL RESEARCH COUNCIL - NRC. Nutrient requeriments of beef cattle. 7.ed. Washington, D.C.: National Academy Press, 1996. 242p.

PERUCHENA, C.O. Suplementación de bovinos para carne sobre pasturas tropicales, aspectos nutricionales, productivos y economicos. In: REUNIÃO ANUAL DA SOCIEDADE BRASILEIRA DE ZOOTECNIA, 36., 1999, Porto Alegre. Palestras... São Paulo: SBZ/Gmosis, [1999] 17par. CDROM.

PRADO, I.N. Características da produção da carne bovina. In: PRADO, I.N. (Ed.) Comercialização e estratégias competitivas na cadeia de carnes no Brasil. 1.ed. Maringá: Eduem, 2000. p.17-55.

RESTLE, J.; VAZ, F.N.; ALVES FILHO, D.C. et al. Efeito da suplementação energética sobre a carcaça de vacas de diferentes idades, terminadas em pastagem cultivada de estação fria sob pastejo horário. Revista Brasileira de Zootecnia, v.30, n.3, p.1076-1083, 2001.

WILM, H.G.; COSTELO, O.F.; KLIPPE, G.E. Estimating forage yield by the double sampling method. Journal of the American Society of Agronomy, v.36, n.1, p.194-203, 1994.

ZIMMER, A. H.; EUCLIDES, V.P.B.; MACEDO, M.C.M. Manejo de plantas forrageiras do gênero 4. In: PEIXOTO, A.M.; MOURA, J.C.; FARIA, V.P. (Eds.) Plantas forrageiras de pastagens. Piracicaba: Fundação de Estudos Agrários, 1995. v.13, p.101-143.

Recebido em: 23/07/03

Aceito em: 25/09/04 